BRAVZULIAN JOURNAL

OF MEDICAL AND BIOLOGICAL RESHARCH

www.bjournal.com.br
ISSN 0100-879X

Volume 44 (6) 497-605 June 2011

BIOMEDICAL SCIENCES

AND

CLINICAL INVESTIGATION

Braz J Med Biol Res, June 2011, Volume 44(6) 500-513

doi: 10.1590/S0100-879X2011007500064

Trends in adjuvant development for vaccines: DAMPs and PAMPs as potential new adjuvants

E.N. Miyaji, E. Carvalho, M.L.S. Oliveira, I. Raw and P.L. Ho

The Brazilian Journal of Medical and Biological Research is partially financed by

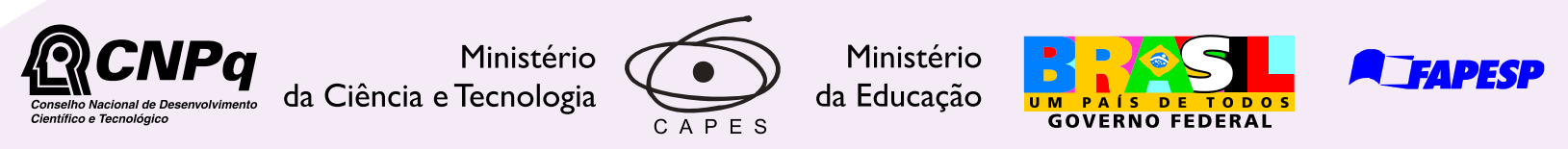

Institutional Sponsors
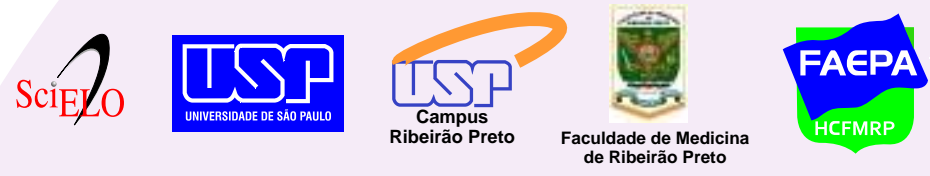

de Ribeirão Pretic

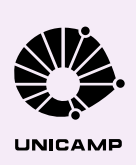

Ф SHIMADZU H

GE Healthcare
Hotsite of proteomics metabolomics developped by:

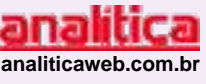




\title{
Trends in adjuvant development for vaccines: DAMPs and PAMPs as potential new adjuvants
}

\author{
E.N. Miyaji*, E. Carvalho*, M.L.S. Oliveira, I. Raw and P.L. Ho \\ Centro de Biotecnologia, Instituto Butantan, São Paulo, SP, Brasil
}

\begin{abstract}
Aluminum salts have been widely used in vaccine formulations and, after their introduction more than 80 years ago, only few vaccine formulations using new adjuvants were developed in the last two decades. Recent advances in the understanding of how innate mechanisms influence the adaptive immunity opened up the possibility for the development of new adjuvants in a more rational design. The purpose of this review is to discuss the recent advances in this field regarding the attempts to determine the molecular basis and the general mechanisms underlying the development of new adjuvants, with particular emphasis on the activation of receptors of innate immune recognition. One can anticipate that the use of these novel adjuvants will also provide a window of opportunities for the development of new vaccines.
\end{abstract}

Key words: Adjuvant; Vaccine; Innate immunity; DAMP; PAMP

\section{Introduction}

Vaccines have proven to be a very effective strategy to reduce the burden of infectious diseases. One human viral pathogen has already been totally eradicated, a veterinary viral disease is likely to be declared vanquished in the following months, and several other infectious diseases have been controlled by the use of vaccines. Smallpox is a human disease caused by the virus variants Variola major or Variola minor and was responsible for killing up to 2 million people/year and disfiguring millions more until its control. This terrible disease was considered to be eradicated after 30 years of vaccination efforts worldwide. On December 9, 1979, the World Health Organization (WHO) announced the eradication of smallpox, the first infectious disease eradicated in the World, using basically a live cow pox virus vaccine first developed by Jenner in 1796. Recently, on October 14, 2010, the Food and Agriculture Organization of the United Nations (FAO) announced that a 16-year effort has succeeded in controlling rinderpest, a deadly infectious disease of cattle caused by a virus closely related to canine distemper and human measles viruses, and that the field surveillance has ended. For this disease to be declared eradicated, the World Organization for Animal Health has to issue an official declaration recognizing the demise of the rinderpest disease at its May 2011 Meeting. Again, rinderpest in cattle is being eradicated through the use of an attenuated goat-adapted virus developed by Walter Plowright through serial passages of the pathogen in tissue culture (1). This will be the first veterinary infectious disease and also the second human disease eliminated from the face of the planet (2). These accomplishments raise the natural question of which infectious disease will be the next to be eradicated.

The principle of prophylactic vaccination against infectious diseases is the priming of a specific adaptive immune response that will protect the host from a subsequent exposure to a pathogen. Vaccines can be composed of live attenuated organisms, killed whole-cell organisms or subunit components (3). The yellow fever and small pox vaccines are examples of live-attenuated vaccines and are able to induce potent and protective immune responses that can last for several decades. The whole cell pertussis and the whole virus influenza vaccines are examples of whole organisms inactivated through chemical treatment. Examples of subunit vaccines are the hepatitis $B$ and the acellular pertussis vaccines. In contrast to earlier developments, new vaccines tend to be composed of more defined components and though this strategy has led to safer profiles with less reactogenicity, it has become clear that when more purified components are used for vaccine formulations, weaker immune responses tend to be elicited.

Correspondence: P.L. Ho, Centro de Biotecnologia, Instituto Butantan, Av. Vital Brasil, 1500, 05503-900 São Paulo, SP, Brasil.

E-mail: hoplee@butantan.gov.br

*These authors contributed equally to this review.

Received February 28, 2011. Accepted April 18, 2011. Available online May 13, 2011. Published June 13, 2011. 
Whereas vaccines composed of an entire organism present several antigens to the immune system and usually have sufficient immunostimulatory activity by themselves, vaccines composed of purified antigens commonly need the addition of components to potentiate the immune response. Such components are known as adjuvants.

Aluminum salts (alum) were the first adjuvants licensed for human vaccines in the 1920's and the licensure of novel adjuvants took about 80 years (4). One of the main reasons for this long gap is that the development of adjuvants was purely empirical, since the principles of adjuvant activity were largely unknown. Moreover, some adjuvants, such as Freund's adjuvant, were shown to elicit strong immune responses, but the associated reactogenicity was not acceptable for licensure. Recent advances in the understanding of the interplay between the innate and adaptive immune systems have shed light on the mechanisms of action of adjuvants. Based on this knowledge, development of new adjuvants can be now more rationally pursued. The role of the innate immunity activation in the adaptive immune response elicited by vaccines and also the use of complex adjuvant formulations for the development of efficient and cost-effective vaccines will be discussed in this review.

\section{Innate immunity}

The development of the immune system was a fundamental evolutionary acquisition that allowed the survival of organisms against internal and external insults. The immune system of jawed vertebrates can be divided into the innate and adaptive arms, which interact constantly as a unique system. The innate immune system is phylogenetically more ancient and is the first line of defense (5), being able to induce a rapid and nonspecific response to the encounter of a pathogen, in contrast to the adaptive immune system, which depends on B and T lymphocytes. For instance, the adaptive immune system involves clonal selection of antibody-producing $B$ cells to respond to foreign antigens and, although it works well, it has a major limitation since it takes 4 to 7 days to ramp up. During this period of time, pathogens can overwhelm and disseminate into the host. Dendritic cells (DCs), macrophages, neutrophils, natural killer (NK) cells and $\gamma \delta \mathrm{T}$ lymphocytes are cellular components of the innate immune system that respond to common structures shared by the vast majority of threats. Microorganisms can be in general sensed through the recognition of common components, the pathogen-associated molecular patterns (PAMPs). PAMPs are recognized through binding to receptors of the innate immune system, the pattern recognition receptors (PRRs). Several classes of PRRs have been described, including the Toll-like receptors (TLRs), the retinoic acid-inducible gene I (RIG-I)-like receptors (RLRs), the nucleotide-binding domain and leucine-rich repeat containing receptors (NLRs), the C-type lectin receptors (CLRs), and others (Figure 1). In this review, we will discuss in more detail the PRRs of the TLRs and NLRs classes. Other interesting reviews on RLRs or CLRs can be found elsewhere (6-12). Thirteen TLRs have been identified in mammals, which can recognize many structurally different ligands through their distinct extra-domain $(13,14)$. Ten TLRs (TLRs1-10) have been described in humans and their ligands have also been identified, except for TLR10 $(15,16)$. Mice do not present a functional TLR10 due to an insertional mutagenesis of a retrovirus but have additional TLRs (TLRs11-13), besides those in common with man (TLRs1-9). The TLRs11-13 have been lost from the human genome (13). TLRs can be located on the cell surface or in the membranes of endosomes and have different specificities for microbial components such as lipopolysaccharide (LPS) from Gram-negative bacteria (TLR4), lipoteichoic acid from Gram-positive bacteria (TLR2), flagellin (TLR5), and single-stranded RNA (TLR7) (Table 1). Depending on the TLR, they can form either a homodimer or a heterodimer. In fact, the activation of a TLR is more complex and may involve other components, accessory and co-receptor molecules depending on the system. Furthermore, TLRs bind not only to PAMPs but also to danger-associated molecular patterns (DAMPs), most of them of endogenous origin (Table 1). As an example of activation by PAMPs, LPS associates with the plasma protein LPS-binding protein (LBP) that binds to CD14, a glycosylphosphatidylinositol- and leucine-rich repeat containing protein. CD14 delivers the LBP-LPS to TLR4 that also recruits the MD-2 molecule (Figure 2). A complex composed of two copies of TLR4-MD-2-LPS initiates the cascade of intracellular signaling (17). On the other hand, high mobility group B-1 (HMGB1) protein is an endogenous DAMP that also binds to TLR4 and requires MD-2 and CD14 for TLR4 activation. Furthermore, HMGB1 can also mediate LPS transfer to CD14 to initiate a TLR4-mediated pro-inflammatory response, illustrating the complexity of interactions involving PAMPs, DAMPs and endogenous activators (18). In fact, this complexity is much higher, since the endogenous ligands, besides functioning as activators, can also bind TLRs and function as suppressors, helping to control the inflammatory response potentially elicited by TLR activation. Recent findings are contributing to the understanding of how exogenous and endogenous factors activate TLRs and, although some evidence shows some overlap in the molecular machinery, DAMPs present some distinct mechanisms to PAMPs, resulting in different outcomes (19). Upon stimulation, TLRs interact with specific Toll/interleukin (IL)-1R (TIR) domain-containing adaptor proteins, which provide specificity for TLR signaling. The binding of LPS to TLR4 leads to signaling through two different pathways. The first one involves the adaptor molecules TIRAP and MyD88 when pathogen-induced dimerization of TLR4 recruits MyD88 molecules and IRAK kinase enzymes that hierarchically assemble into a left-handed helical oligomerized tower for proper signal transduction, triggering NF-KB activation 


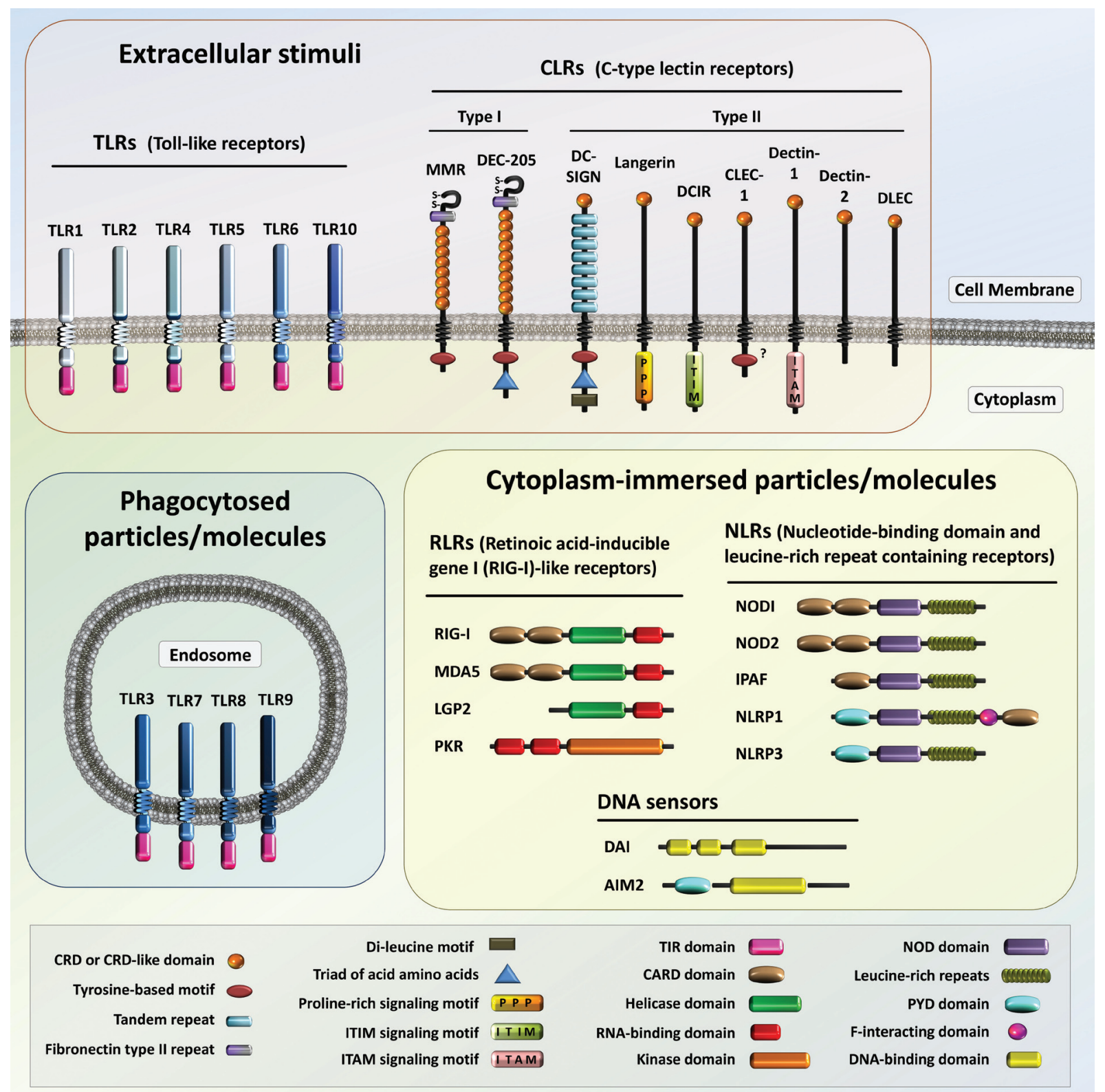

Figure 1. Schematic representation of the major classes of pattern recognition receptors (PRRs) of the innate immune system. Members of the Toll-like receptors (TLRs) can be found on the cell surface membrane (TLR1/2/4/5/6/10) as well as in the membrane of endosomes (TLR3/7/8/9); C-type lectins can be of type I or type II. Type I C-type lectins have an N-terminal domain displayed in the extracellular portion of the molecule, containing a cysteine-rich repeat (S-S), a fibronectin type II repeat (FN) and 8-10 carbohydrate recognition domains (CRDs), which bind ligands in a $\mathrm{Ca}^{2+}$-dependent manner. Type II C-type lectins contain only one CRD at their carboxy-terminal extracellular domain. Nucleotide-binding oligomerization domain (NOD) leucine-rich repeat (LRR)-containing receptors (NLRs) are cytoplasmic PRR receptors and the central components of the inflammasomes; the retinoic acid-inducible gene I (RIG-I)-like receptors (RLRs) are also cytoplasmic PRR receptors. Retinoic acid-inducible protein I (RIG-I) is an interferon-inducible protein containing a caspase recruitment domain (CARD) and a $\mathrm{DExD} / \mathrm{H}$ box helicase domain and has been described as a cytoplasmic dsRNA sensor and considered to be the prototype of this family of PRRs. Other miscellaneous PRRs are also shown (DNA sensors DAl and AIM2). The different kinds of motifs, domains, repeats, and features that compose modularly the PRRs are also shown. AIM2 = absent in melanoma 2; CLEC-1 = C-type lectin receptor 1; DAI = DNA-dependent activator of interferon-regulatory factors; DCIR = dendritic cell immunoreceptor; DC-SIGN = dendritic-cell specific ICAM-3 grabbing nonintegrin; DEC-205 = dendritic cell receptor for endocytosis 205; DLEC = dendritic cell lectin; IPAF = ice protease-activating factor; ITAM = immunoreceptor tyrosine-based activation motif; ITIM = immunoreceptor tyrosine-based inhibitory motif; LGP2 = laboratory of genetics and physiology 2; MDA5 = melanoma differentiation-associated gene 5; MMR = macrophage mannose receptor; NLRP1/3 = nucleotide-binding oligomerization domain, leucine-rich repeat and pyrin domain containing 1/3; PKR = double-stranded RNA activated protein kinase; PYD = Pyrin domains; TIR = Toll/interleukin-1 receptor homology domain. Based on Refs. 10 and 32. 
and expression of pro-inflammatory cytokine genes (20). In this pathway, the transcription factor interferon regulatory factor 5 (IRF5) is also activated and translocated to the nucleus and binds to interferon-stimulated response element (ISRE) regions present in the promoter segments of pro-inflammatory cytokines $(13,21)$. Interestingly, IRF5 is involved in the transcription of pro-inflammatory cytokines by all TLRs tested so far (22). The other pathway is MyD88independent, involving the adaptor molecules TRAM and TRIF and leads to the expression of interferon- $\beta$ (IFN- $\beta$; Figure 2) (23). Both pathways are highly complex and are initiated by the cytoplasmic TIR domain homologous to the IL-1 receptor portion of the TLR.

NLRs include a large family of intracellular sensors that can detect both pathogens and stress signals (24). Again, the concept of recognition of PAMPs can thus be further extended to the idea of recognition of both extrinsic and intrinsic DAMP signals (Table 1). The NLR is composed of a central nucleotide oligomerization domain (NOD), an $\mathrm{N}$ terminal pyrin or a caspase recruitment domain (CARD) and a C-terminal leucine-rich repeat (LRR) (Figure 1). Whereas stimulation of NOD1 and NOD2 (Figure 1), members of the NLR family, results primarily in the activation of the pro-inflammatory gene expression response (25), other NLRs (like NLRP3), activate the caspase- 1 that processes the inactive IL-1 $\beta$ and IL-18 precursors and eventually results in the secretion of the IL-1 and IL-18 active forms. The NLRP3 does not present the CARD domain, being incapable of recruiting procaspase-1. The recruitment of procaspase- 1 by NLRP3 is mediated by another molecule, apoptosis-associated speck-like (ASC) protein containing a CARD, via interaction with the NLRP3 pyrin domain, resulting in the multimeric structure of the inflammasome (Figure 3) $(26,27)$. The inflammasome comprising NLRP3 can be activated by several triggers, including markers of host/environment-derived molecules (DAMPs) or by PAMPs. For instance, NLRP3 can be activated by ATP and $\mathrm{K}^{+}$efflux, by crystalline/particulate ligands and by reactive oxygen species (ROS) (28). Interestingly, NLRP3 directly binds ATP and mutation of the nucleotide-binding domain of NLRP3 reduces ATP binding, caspase-1 activation, IL-1 production, cell death, macromolecular complex formation, self-association, and association with the inflammasome component ASC, suggesting a crucial role of ATP in inflammasome activation (29). It has been proposed that NLRs provide a second line of defense against microorganisms, sensing membrane disruption caused by pathogens that have evaded cell surface PRRs. Again, the interconnections and cooperation between the systems are evident. For example, during the infection, the microorganism induces TLR-dependent cytosolic accumulation of the inactive IL-1 $\beta$ precursor. Activation of the inflammasome by molecules recognized by NLRP3 will catalyze the processing of the IL-1 $\beta$ precursor induced by TLR-dependent mechanisms (26,30-32). Besides cooperation, redundancy is also a feature of PRRs. Virus double-stranded RNAs are recognized by both TLR3 and RIG-1/MDA5 from RLRs. Bacterial flagellin is recognized by TLR5 and cytosolic and monomeric flagellin is recognized by Ipaf from the NLR innate system $(33,34)$.

\section{Modulation of adaptive immunity by innate immunity}

In addition to their role in the innate immune response, PAMPs and DAMPs have an important function in T-cell differentiation and regulation of the adaptive immunity. The adaptive immunity involves the development of a specific response after a first encounter with a pathogen or antigen. The host thus becomes "primed" and is able to respond more rapidly to a subsequent exposure to the pathogen. Adaptive responses involve the engagement of specific $B$ and $T$ lymphocytes. In contrast to the innate immune system, which has a limited number of receptors that recognize conserved patterns, the specificity of the adaptive immune system is achieved through gene rearrangements and clonal selection (and expansion) from a broad repertoire of antigen-specific receptors on naive lymphocytes. It has become recently clear that signaling via the activation of the innate immune system is necessary for adequate adaptive responses against a pathogen. Activation of PRRs leads to the recruitment of cells of the immune system and to activation of antigen-presenting cells (APCs), increasing antigen uptake, processing and peptide presentation through major histocompatibility complex (MHC) I and/or II molecules. It also induces expression of cell-surface molecules, receptors and co-stimulatory molecules, required for T-cell contact and activation. Maturation of APCs is essential for priming antigen-specific naive T cells, influencing both the magnitude and the type of the $\mathrm{T}$ - and $\mathrm{B}$-cell responses as well as the induction of memory cells (Figure 4). After maturation, APCs migrate to secondary lymphoid tissues where they present the processed antigenic peptides to naive $\mathrm{CD}^{+}$ T-helper cells through $\mathrm{MHC}$ II or to $\mathrm{CD}^{+}$cytotoxic T cells by the $\mathrm{MHC}$ I molecule. For instance, the activation of naive T-helper lymphocytes is triggered by the T-cell receptor (TCR) bound to the antigenic peptide presented in the MHC II context. However, co-stimulatory and co-receptor molecules are also necessary to trigger a proper response. CD80/CD86, CD40, CD54 and CD58 on APCs bind to CD28, CD154, CD11a, CD2 on T cells, respectively, establishing a complex and a close interaction (immunological synapse) between the cells (35). Furthermore, this interaction in the presence of specific immunomodulatory molecules (IL-4, IL-2, IFN- $\gamma$, IL-12, transforming growth factor- $\beta$ (TGF- $\beta$ ), IL-6, IL-13, IL-23, and/or other cytokines) will also define the type of lineage commitment of $\mathrm{CD}^{+}{ }^{+} \mathrm{T}$ cells towards Th1, Th2, Th9, Th17, Th22, Tfh, iTreg, or NKT. In this regard, IL-12 is an important cytokine in the context of naive T cells polarizing to Th1 cells, whereas IL-4 is essential for 
Table 1. Pattern-recognition receptors (PRRs).

\begin{tabular}{|c|c|c|c|}
\hline \multirow[t]{2}{*}{ PRRs } & \multicolumn{2}{|l|}{ Ligands (DAMPs and PAMPs) } & \multirow{2}{*}{$\begin{array}{l}\text { Cellular } \\
\text { localization }\end{array}$} \\
\hline & Exogenous & Endogenous & \\
\hline \multicolumn{4}{|c|}{ Human TLRs (homo- or heterodimers) } \\
\hline TLR1/TLR2 & Triacyl lipopeptides (mycobacteria and Neisseria) & a-defensins & Cell surface \\
\hline TLR2 & $\begin{array}{l}\text { Lipoproteins, peptidoglycan, lipoarabinomannan, porins, } \\
\text { envelope glycoproteins, GPI-mucin, phospholipomannan, } \\
\text { zymosan, a-glycan (various pathogens, such as } \\
\text { Gram-positive and Gram-negative bacteria, mycobacteria, } \\
\text { Neisseria, viruses, protozoa, Candida, fungi) }\end{array}$ & Surfactant protein A & Cell surface \\
\hline TLR2/TLR4 & Glucuronoxylomannan (Cryptococcus neoformans) & $\begin{array}{l}\text { HSP60, HSP70, Gp96, HMGB1, } \\
\text { surfactant protein D serum } \\
\text { amyloid A, byglycan }\end{array}$ & Cell surface \\
\hline TLR2/TLR6 & $\begin{array}{l}\text { Diacyl lipopeptides, lipoteichoic acid (Mycoplasma, } \\
\text { Gram-positive bacteria) }\end{array}$ & Versican & Cell surface \\
\hline TLR3 & dsRNA & mRNA & Endosome \\
\hline TLR4 & $\begin{array}{l}\text { LPS, envelope glycoproteins, glycoinositolphospholipids, } \\
\text { mannan (Gram-negative bacteria, viruses, protozoa, } \\
\text { Candida) }\end{array}$ & $\begin{array}{l}\text { Fibronectin extra domain a, } \\
\text { fibrinogen, tenascin-C, neutrophil } \\
\text { elastase, lactoferrin, oxidized } \\
\text { LDL, saturated fatty acids, } \\
\text { heparan sulfate fragments, } \\
\text { hyaluronic acid fragments }\end{array}$ & Cell surface \\
\hline TLR5 & Bacterial flagellin & & Cell surface \\
\hline TLR7/TLR8 & ssRNA (RNA viruses) & ssRNA & Endosome \\
\hline TLR9 & CpG DNA, hemozoin (viruses, bacteria, protozoa) & Chromatin-IgG complexes & Endosome \\
\hline TLR10 & Unknown & & Cell surface \\
\hline \multicolumn{4}{|l|}{ RLRs } \\
\hline RIG-I & Short dsRNA, 5'-triphosphate RNA (viruses) & & Cytoplasm \\
\hline MDA5 & Long dsRNA (viruses) & & Cytoplasm \\
\hline \multicolumn{4}{|l|}{ NLRs } \\
\hline NOD1 & Peptidoglycans, diaminopimelic acid (Gram-negative bacteria) & & Cytoplasm \\
\hline NOD2 & $\begin{array}{l}\text { Peptidoglycans, muramyl dipeptide (Gram-negative and } \\
\text { Gram-positive bacteria) }\end{array}$ & & Cytoplasm \\
\hline NLRP1 & $\begin{array}{l}\text { Muramyl dipeptide, Bacillus anthracis lethal toxin } \\
\text { (Gram-negative and -positive bacteria, bacterial toxins) }\end{array}$ & & Cytoplasm \\
\hline NLRP3 & $\begin{array}{l}\text { RNA, DNA, muramyl dipeptide, bacterial toxins, } \\
\text { silica, asbestos, UVB radiation, trinitrophenylchloride, } \\
\text { trinitrochlorobenzene, dinitrofluorobenzene, (viruses, bacteria, } \\
\text { environment) }\end{array}$ & $\begin{array}{l}\text { ATP, hyaluronic acid, amyloid } \beta \\
\text { peptide, urate crystals, elevated } \\
\text { extracellular glucose, reactive } \\
\text { oxygen species }\end{array}$ & Cytoplasm \\
\hline IPAF & Cytosolic bacterial flagellins & & Cytoplasm \\
\hline \multicolumn{4}{|l|}{ C-type lectins } \\
\hline MMR & Mannose, fucose & Mannose, fucose, sialyl Lewis $X$ & Cell surface \\
\hline Dectin-1 & $\beta$-glucan & & Cell surface \\
\hline DC-SIGN & N-acetylglucosamine-mannose, mannan, HIV-1 (gp120), SIV & $\begin{array}{l}N \text {-acetylglucosamine-mannose, } \\
\text { ICAM-2, ICAM-3 }\end{array}$ & Cell surface \\
\hline
\end{tabular}

ATP = adenosine triphosphate; $C p G$ DNA = C-phosphate-G DNA; DAMPs = danger-associated molecular patterns; DC-SIGN = dendritic-cell specific ICAM-3 grabbing non-integrin; dsRNA = double-stranded RNA; GP = glycoprotein; GPI-mucin = glycosylphosphatidylinositol-anchored mucin; HIV = human immunodeficiency virus; HMGB1 = high-mobility group protein B1; HSP = heat-shock protein; ICAM = intercellular adhesion molecules; IgG = immunoglobulin G; IPAF = ice protease-activating factor; LDL = low-density lipoprotein; LPS = lipopolysaccharide; MDA5 = melanoma differentiation-associated gene $5 ;$ MMR = macrophage mannose receptor; mRNA = messenger RNA; NLRP1/3 = nucleotide-binding oligomerization domain, leucine-rich repeat and pyrin domain containing 1/3; NLRs = nucleotide-binding domain and leucine-rich repeat receptors; NOD = nucleotide-binding oligomerization domain; PAMPs = pathogenassociated molecular patterns; RIG-I = retinoic acid-inducible gene I; RLRs = retinoic acid-inducible gene I (RIG-I)-like receptors; SIV = Simian immunodeficiency virus; ssRNA = single-stranded RNA; TLR - Toll-like receptor. Based on published reviews $(19,21,32,80)$. 


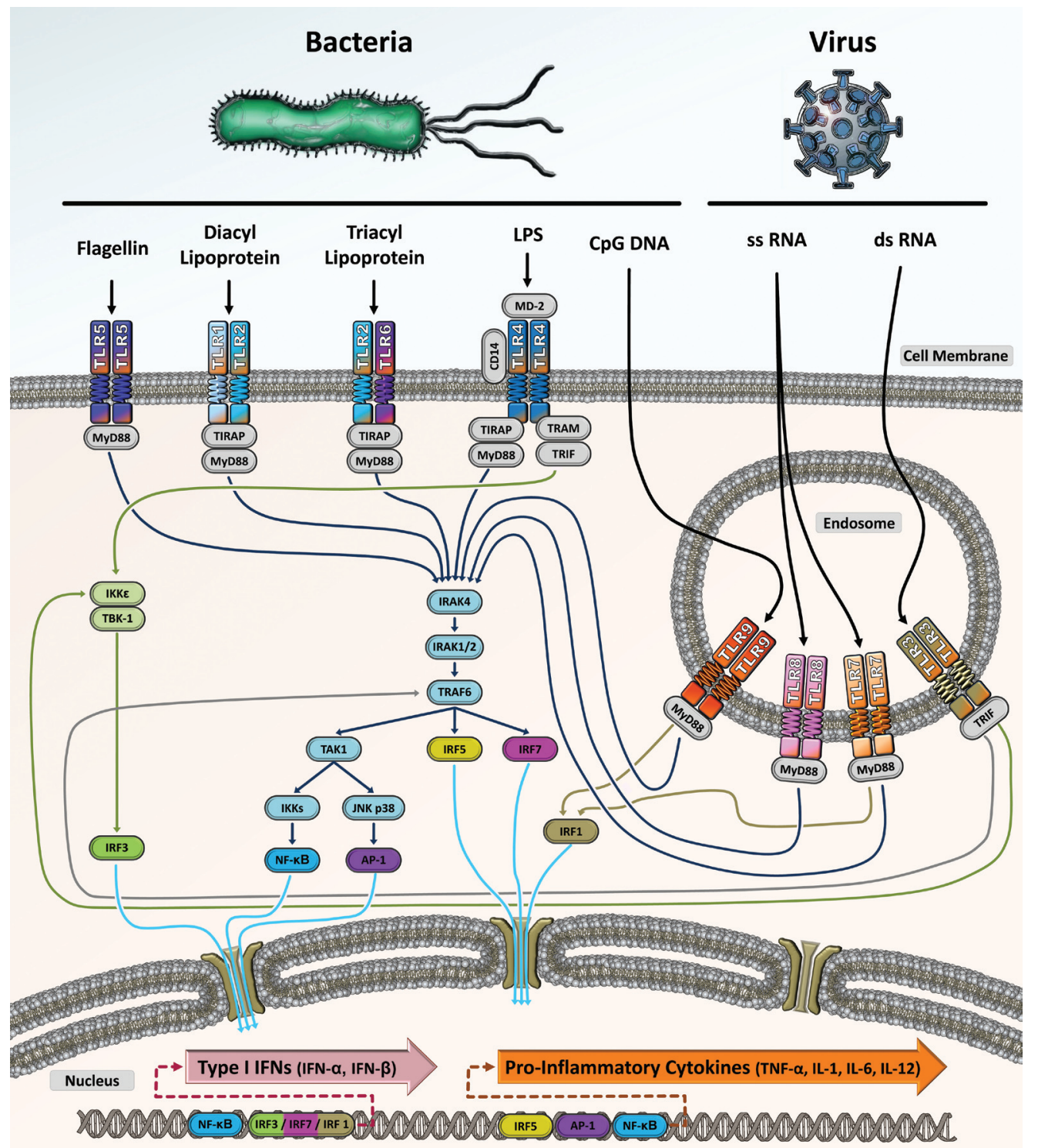

Figure 2. Schematic representation of some possible Toll-like receptor (TLR) signaling events stimulated during the infection by bacteria and viruses. Some ligands for specific TLRs are indicated. TLRs and IL-1R share common signaling events in general. Following ligand binding, TLRs dimerize to form homo- or heterodimers (depending on the type of TLR) and undergo conformational changes that recruit Toll/interleukin-1 receptor (TIR) homology domain-containing adaptor molecules. MyD88 was the first adaptor molecule identified and is involved in signaling induced by all TLRs, with the exception of TLR3. Depending on the TLR, another MyD88-independent pathway may exist, as in the cases of TLR3/4. An MyD88-dependent pathway triggers a cascade of events leading to the activation of IRAK kinase enzymes, which trigger NFKB transcription factor activation and pro-inflammatory cytokine gene expression. Depending on the TLR stimulation, the MyD88-dependent pathway can also activate the interferon regulatory factor (IRF) family of transcription factors IRF1, IRF5 or IRF7 by phosphorylation mechanisms, resulting in homo- or heterodimers, their translocation to the nucleus and, in association with transcriptional co-activators, binding to target interferon-stimulated response elements (ISREs). The MyD88-independent pathway activates the transcription factor IRF3 through the TRIF adaptor that stimulates the expression of interferon- $\beta$. IRF1, IRF3 and IRF7 are involved in the transcription control of type I interferons, whereas IRF5 is involved in the transcription of pro-inflammatory cytokines by all TLRs tested so far. AP-1 = activator protein $1 ;$ CD14 = cluster of differentiation 14; CpG DNA = C-phosphate-G DNA; ds RNA = double-stranded RNA; IFN = interferon; IKKs = I kappa B kinases; IKKE = I kappa B kinase epsilon; IL = interleukin; IRAK = interleukin-1 receptor associated kinase; JNK p38 = c-Jun N-terminal kinase and p38 mitogenactivated protein kinase; LPS = lipopolysaccharide; MD-2 = myeloid differentiation factor 2; MyD88 = myeloid differentiation primary response gene 88; NF-KB = nuclear factor-kappa B; ssRNA = single-stranded RNA; TAK = TGF- $\beta$ activated kinase; TBK-1 = TANK-binding kinase 1; TANK = TRAF family member-associated NF-KB activator; TIRAP = Toll-interleukin-1 receptor domain containing adaptor protein; TNF = tumor necrosis factor; TRAF = TNF receptor associated factor; TRAM = Toll-receptor-associated molecule; TRIF = TIR domain-containing adapter inducing IFN- $\beta$. Based on Refs. 21 and 32. 
Th2 cells. Therefore, the microenvironment induced by the DAMPs and PAMPs on APCs in concert with the antigen presentation on MHC II context in this case modulates and also defines the type of the resulting adaptive im- mune response against the pathogen (Figure 4). The use of DAMPs based on aluminum salts will produce polarized Th2 cells that produce IL-4 and IL-13 cytokines, leading to isotype class switching and affinity maturation, generation

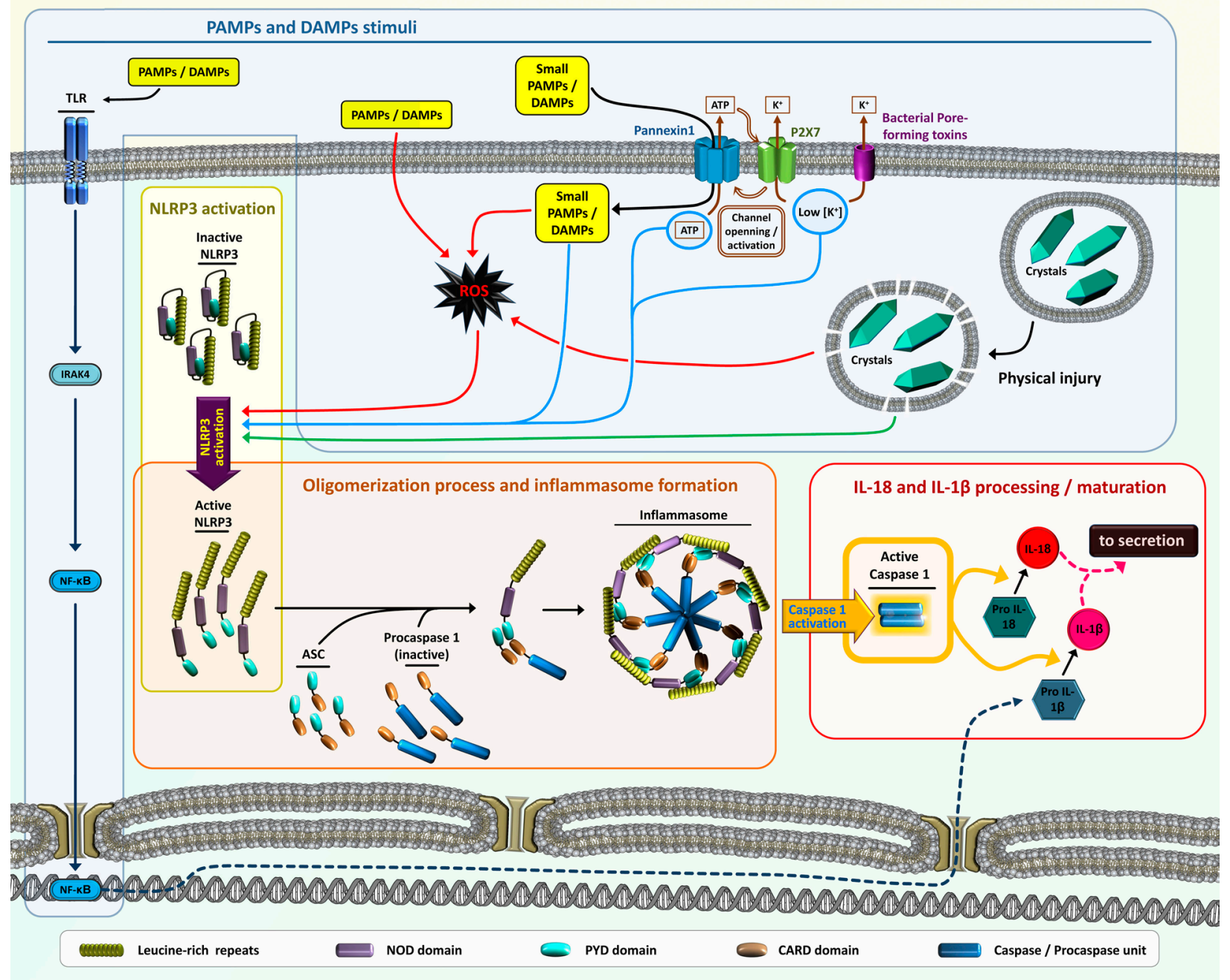

Figure 3. Schematic representation of inflammasome activation. Nucleotide-binding domain, leucine-rich repeat (NBD-LRR) proteins (NLRs) are comprised by 22 human genes. NLRs are activated by host/environment-derived molecules (DAMPs) or by pathogenassociated molecular patterns (PAMPs). NLRP3 is one member of these NLR proteins. NLRP3 can be activated by ATP and $\mathrm{K}^{+}$efflux, triggering a P2X7-dependent pore formation by the pannexin-1 hemichannel from where small PAMPs and DAMPs can reach the cytosol to activate NLRP3 resulting in the inflammasome formation. Alternatively, NLRP3 can be activated by crystalline/particulate ligands, which can lead to lysosomal rupture and cathepsin B leakage, activating the NLRP3 inflammasome in the cytosol. Generation of reactive oxygen species (ROS) by PAMPs and DAMPs can also activate the inflammasome. Activation of the inflammasome involves the formation of an oligomeric complex composed of activated NLRP3, ASC and Procaspase 1, primarily through the CARD and Pyrin (PYD) domains, resulting in the formation of penta- or heptameric inflammasome structures. Procaspases 1 undergo autoactivation in the inflammasomes to active caspases 1, leading to the processing and maturation of the pro-inflammatory IL-1 $\beta$ and IL-18 to mature IL-1 $\beta$ and IL-18. Several pattern recognition receptor (PRR) activations such as those induced by TLR ligands, induce the expression of pro-inflammatory cytokines, among them pro-IL-1 $\beta$, that will be substrates of caspases 1 , therefore connecting and potentiating these two (TLRs and NLRs) innate immune responses. ASC = apoptosis-associated speck-like protein containing a caspase recruitment domain; ATP = adenosine triphosphate; CARD = caspase recruitment domain; DAMPs = danger-associated molecular patterns; IL = interleukin; IRAK = interleukin-1 receptor associated kinase; NF-KB = nuclear factor-kappa B; NLRP3 = nucleotide-binding oligomerization domain, leucine-rich repeat and pyrin domain containing 3; NOD = nucleotide-binding oligomerization domain; P2X7 = P2X purinoreceptor 7; TLR = Toll-like receptor. Based on Refs. 24 and 26. 


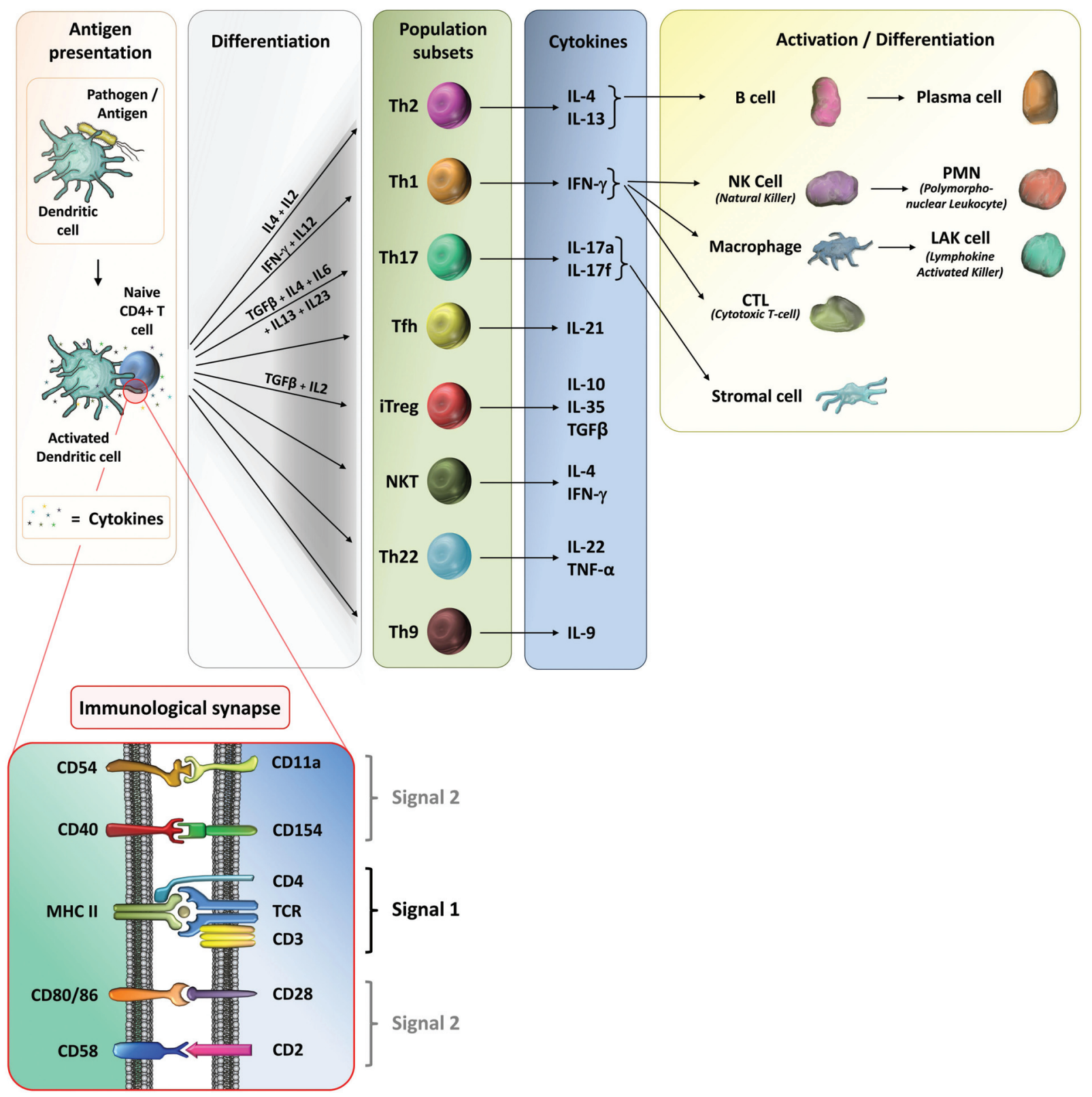

Figure 4. General view of the stimulation and differentiation of $\mathrm{CD} 4^{+} \mathrm{T}$ lymphocytes by dendritic cells after pathogen or antigen encounter. The pathogen or antigen is processed and the resulting antigenic peptides are presented to $\mathrm{CD} 4^{+} \mathrm{T}$ cells by the MHC II molecules (signal 1) in a true immunological synapse. Co-receptors, co-stimulatory molecules (signal 2) and cytokines (for instance, IL-4, IL-12 for Th2 differentiation) are important to drive the $\mathrm{CD} 4{ }^{+} \mathrm{T}$ cells to their final differentiation to Th2, Th1 or other population subset of cells. The antigen presentation environmental context is seminal to define this differentiation and this is dictated by the pattern recognition receptors (PRRs) and their ligands, showing the importance of the innate immune response in the modulation of the acquired immunity by the adaptive immune system, interconnecting both branches of the immune response of an organism. Therefore, modulation of the immune response to a vaccine antigen can be achieved using appropriate adjuvants, based on PAMP and DAMP agonists of PRRs. $\mathrm{CD}$ = cluster of differentiation; IFN- $y=$ interferon gamma; IL = interleukin; iTreg = inducible T regulatory cells; $\mathrm{MHC}=$ major histocompatibility complex; NKT = natural killer T cells; TCR $=\mathrm{T}$ cell receptor; $\mathrm{Tfh}=\mathrm{T}$ follicular helper cells; $\mathrm{TGF}-\beta=$ transforming growth factor beta; Th = T-helper cell; TNF- $\alpha=$ tumor necrosis factor alpha. Based on Ref. 35. 
of memory B cells and differentiation of B cells into mature plasma antibody-secreting cells after recognition of an antigen by mature naive $B$ cells.

During a natural infection, several antigens are presented to the host in a context of stimulation of the innate immune system by different PAMPs (Figure 2). Usually, an infection can lead to long-lived protection against the pathogen. Successful live-attenuated vaccines can mimic a natural infection and also induce robust adaptive immune responses. The live attenuated yellow fever vaccine YF-17D has been successfully used for the control of the disease since 1945. It induces a polyvalent immune response that includes the production of cytotoxic T cells, a mixed Th1/ Th2 cell profile and neutralizing antibodies that can persist up to 40 years (36). Recent results have helped to elucidate the mechanism of protection elicited by this vaccine. Culture of human monocyte-derived DCs with YF-17D resulted in the induction of pro-inflammatory cytokines, including IL-6 and tumor necrosis factor- $\alpha$ (TNF- $\alpha$ ). YF-17D was also an efficient inducer of the co-stimulatory molecules CD80 and CD86. Furthermore, dendritic cells derived from knockout mice for TLR2, TLR7, TLR8, TLR9 or the adaptor molecules MyD88 and TIRAP showed decreased secretion of proinflammatory cytokines or reduced activation of the NF-KB pathway when cultured with YF-17D. In vivo, immunization of MyD88-1- mice with YF-17D led to diminished numbers of $\mathrm{CD}^{+}$and $\mathrm{CD}^{+} \mathrm{T}$ cells expressing IFN-Y (37). It is thus clear that YF-17D mediates its immunogenicity, in part, by signaling the innate immune system through multiple TLRs.

In contrast to earlier vaccines, newly developed vaccines tend to be more defined, including subunits of the pathogen and not entire organisms. Though these formulations have improved safety and reactogenicity profiles, they tend to have low immunogenicity by themselves. The lack of signaling through activation of the innate immune system is one of the main reasons for the decreased immune responses of subunit vaccines and the inclusion of adjuvants in the formulation is needed to achieve protective responses in most cases.

\section{Mechanisms of action of adjuvants}

Alum has been the only adjuvant approved for human use for decades and only a few others are currently licensed. MF59, an oil-in-water emulsion, and monophosphoryl lipid A (MPL), present in the adjuvant system AS04, are among the recently licensed adjuvants (Table 2). Some other adjuvant formulations are now undergoing clinical trials and some are expected to be approved soon (38). Adjuvants can alter the delivery of the antigen or act as immunopotentiators, influencing both the amount and the quality of the adaptive immune response, including type and breadth. Delivery can be modified through the slow release of antigen and enhancement of uptake by APCs in emulsions and liposomes, for example, whereas immunopotentiators act through the activation of the innate immune system.

Alum is a very efficient adjuvant for diseases against which a neutralizing antibody response is needed, such as tetanus and diphtheria. It leads to a very high antibody response with a Th2 profile against the antigen in mice, and in humans the immune response tends to be a mix of Th2 and Th1 cells $(39,40)$. Nevertheless, alum is a poor inducer of protective Th1-associated immune response, an important feature for the development of vaccines against intracellular pathogens (41). Alum was thought for a long time to work only through the formation of a depot at the site of inoculation, which would enhance antigen uptake. It has been shown that antigens adsorbed to alum are presented as a particulate form, enhancing internalization by APCs (42). Interestingly, the NLR pathway has been recently described as an important mechanism involved in the adjuvant response of aluminum salts. In vitro, exposure of cells to aluminum salts induces the activation of caspase 1 and the release of its known downstream pro-inflammatory targets, IL-1 $\beta$, IL-18 and IL-33, mediated by NLRP3 (43-49). It has been proposed that alum can cause necrosis, resulting in the production of uric acid, which in turn activates NLRP3. The role of activation of the inflammasome pathway is still controversial since some groups have shown that the NLRP3 pathway might be dispensable for the adjuvant

Table 2. Licensed adjuvants.

\begin{tabular}{lllll}
\hline Adjuvant & Immune active component & Pattern recognition receptors (PRRs) & Major immune response & Vaccine \\
\hline Alum & Aluminum salts & NLRP3 inflammasome & Ab, Th2 (mice) (+Th1 in humans) & Several \\
MF59 & $\begin{array}{l}\text { Squalene in emulsion of } \\
\text { oil/water }\end{array}$ & Pro-inflammatory response (?) & Ab, Th1/Th2 & $\begin{array}{l}\text { Seasonal and } \\
\text { pandemic influenza }\end{array}$ \\
AS03 & $\begin{array}{l}\text { Squalene in emulsion of } \\
\text { oil/water }\end{array}$ & Pro-inflammatory response (?) & Ab, Th1/Th2 & Pandemic influenza \\
AS04 & MPL + alum & TLR4 + NLRP3 inflammasome & Ab, Th1 & HBV, HPV \\
\hline
\end{tabular}

$\mathrm{Ab}=$ antibodies; Alum = aluminum hydroxide; $\mathrm{ASO3}=$ Adjuvant System 03; AS04 = Adjuvant System 04; HBV = hepatitis B virus; HPV = human papillomavirus; MPL = monophosphoryl lipid A; NLRP3 = nucleotide-binding oligomerization domain, leucine-rich repeat and pyrin domain containing 3; Th = T-helper cells; TLR4 = Toll-like receptor 4. 
activity of alum in vivo $(43,46)$. In any case, it seems that NLRP3 is part of a pathway involved in the adjuvanticity of alum and it is possible that other signaling events are involved (Figure 3).

As mentioned, the major drawback of alum is the poor induction of Th1 responses. A promising strategy for the development of new adjuvants is the use of TLR agonists that resemble PAMPs, which could provide a pro-inflammatory environment during the induction of the adaptive response, resulting in Th1-skewed responses. MPL is derived from Salmonella minnesota LPS and is able to bind and activate TLR4 (50). It is interesting to note that while binding of LPS to TLR4 activates both the MyD88-TIRAP and TRIF-TRAM pathways (Figure 2), MPL was shown to activate only the TRIF-TRAM pathway, which accounts for its adjuvant properties and low toxicity (23). Other TLR agonists are also being tested for use as adjuvants, such as immunostimulatory molecules containg repeating sequences of cytosine phosphoguanosine (CpG) dinucleotides targeting TLR9 and the TLR7/8 agonists imiquimod and resiquimod (51).

The idea of inducing potent and protective immune responses through the engagement of several PRRs has led to the concept of combining more than one DAMP or PAMP components in an adjuvant system (Table 2) (52). The RTS,S vaccine against malaria has been tested in trials using different adjuvant formulations and the use of some adjuvant combinations was shown to lead to protection while others cannot. The use of AS02, an oil (squalene)-inwater emulsion of MPL and the saponin QS21, has led to some level of protection in immunized individuals (53). On the other hand, AS03, an oil (squalene)-in-water emulsion, and AS04, a combination of aluminum hydroxide and MPL, induced high antibody levels but no protection. The use of AS01, a liposomal formulation containing MPL and QS21, showed a trend towards improved efficacy when compared to AS02 (54). The combination of adjuvants is thus a very promising approach and some formulations are already approved for human use, such as the vaccines against human papilloma virus (HPV) and hepatitis B virus (HBV) combined with AS04 (Table 2) (52). An analysis of the adjuvant AS04 with HPV antigens given intramuscularly showed that MPL was responsible for induction of cytokines and activation of NF-KB in muscle, as well as infiltration and activation of DCs and monocytes in the draining lymph nodes. Infiltrated cells showed increased expression of the co-stimulatory molecules CD40 and CD86. Furthermore, DCs from mice injected with ovalbumin (OVA) and MPL or OVA and AS04 stimulated more proliferation of Ag-specific CD4 ${ }^{+} \mathrm{T}$ cells compared to DCs from mice injected with OVAand aluminum hydroxide or OVA alone. AS04-induced innate responses thus seem to be due to MPL, with aluminum salts being able to prolong the cytokine response to MPL at the injection site (40). Therefore, new trends in vaccine developments include the use of new adjuvants (PAMPs or DAMPs) based on new PRR agonists as well as the combination of these adjuvants, aiming at the programming of the magnitude and persistence of the desired immune response (55).

\section{Whole-cell pertussis vaccine as adjuvant}

An alternative strategy to enhance the immune response against purified antigens is to take advantage of the adjuvant properties of licensed vaccines composed of whole inactivated organisms. The whole-cell pertussis vaccine (wP) has been used for several decades against whooping-cough and it is still included in the national immunization program in Brazil and in many other countries. Though several developed countries have now replaced it with an acellular formulation composed of purified proteins from Bordetella pertussis, the Pan American Health Organization concluded that there is no reason for Latin American countries to change from cellular to acellular vaccines based on safety and cost-effectiveness analysis (56). Furthermore, various reactogenicity levels of $\mathrm{WP}$ have been reported, which may be related to the strains used in different countries. In fact, a recent paper has described differences in lipooligosaccharide structure and endotoxicity between distinct $B$. pertussis strains (57). Still, new developments are being attempted in Brazil to further reduce reactogenicity problems, such as the development of a new vaccine that has reduced LPS content (wPlow - for wP with low endotoxin level) after an organic solvent extraction, which was incorporated into the manufacturing process. This new vaccine was shown to be safe and to induce similar immune responses in a phase I clinical trial and is a good candidate for replacing the classical WP (58). Since WP will continue to be given at 2, 4, and 6 months of age as part of the triple bacterial vaccine - diphtheria, tetanus and pertussis (DTP) -, it could serve as an adjuvant for co-administered antigens. The principle of its adjuvant activity is to take advantage of the activation of multiple receptors of the innate immune system through the several PAMPs presented in the WP.

The co-administration of wP and pneumococcal surface protein $\mathrm{A}$ ( $\mathrm{PspA}$ ), one of the most promising protein antigens for use as an alternative vaccine against pneumococcal infections, has been tested in this regard. Current pneumococcal conjugate vaccines are able to reduce both carriage and invasive disease caused by serotypes included in the formulations; however, the replacement of prevalent serotypes with non-vaccine serotypes has taken place and has led to reduced efficacy after some years of widespread use in children $(59,60)$. Furthermore, conjugate vaccines have a very high production cost, limiting their use in developing countries. The immunization of mice through the nasal route with the PspA-wP combination elicited higher survival levels after a lethal intranasal challenge with pneumococci when compared to animals immunized with PspA only. Higher anti-PspA IgG levels in the serum and IgA in bronchoalveolar fluid 
samples were detected after immunization with PspA-wP. Not only the amount of antibodies was increased, but $\lg$ G1/lgG2a ratios were also reduced, indicating that the WP was able to modulate the immune response towards PspA to a more balanced polarized Th1 over Th2 immune response. Cross-reactivity with PspA from different pneumococcal strains was also increased. The adjuvant effect of wP did not involve TLR4 signaling, since mice that are non-responsive to TLR4 showed the same results as wild-type animals. Furthermore, the lower LPS content of $w P_{\text {low }}$ did not significantly alter the adjuvant activity (61). The analysis of the local immune responses in the lungs of mice immunized with PspA-wP has further shown a very sharp inflammatory response, characterized by the infiltration of neutrophils and secretion of TNF- $\alpha$ that is rapidly controlled (Oliveira MLS et al., unpublished results). Finally, a single subcutaneous dose of the combination of DTP low (diphtheria - tetanus-wP low) with PspA was also able to induce protection of mice against intranasal pneumococcal challenges (61). Besides LPS, several $B$. pertussis proteins act by subverting the immune system during infection $(62,63)$. Interestingly, some of these components have already been described for their adjuvant properties when combined with antigens (64-67). The pertussis toxin (PT) is probably the best characterized among them and has been shown to increase immune responses against co-administered antigens both through the mucosal and parenteral routes of inoculation $(64,68)$. Although signaling through TLR4 has been implicated in the immunomodulation by $\mathrm{PT}$ (69-71), proliferation of lymphocytes can also be observed in TLR4 knockout mice, thus suggesting other routes of activation (72). The filamentous hemagglutinin (FHA) has also been shown to increase antibody responses towards different antigens when administered to mice through mucosal routes (67). Single inoculation of FHA can induce total antibody production and the secretion of MIP-3a, a chemokine involved in the recruitment of dendritic cells to the site of inoculation. Although several examples of the adjuvant activity of $B$. pertussis proteins can be found in the literature, some contradictory results are also observed. For example, suppression of immune responses in mice was described for both PT and FHA $(62,73)$, which are considered to influence bacterial evasion from the immune system. In contrast to wP, acellular pertussis vaccines, which are composed of pertussis proteins, including PT and FHA, have been shown to decrease the immune response to combined vaccines $(74,75)$. Therefore, the composition of the pertussis vaccine will clearly influence the final result. The essential components of wP for the adjuvant activity towards PspA, leading to protection against pneumococcal infection in mice, are still unknown. The combination of PspA and DTP could incorporate benefits of the adjuvant activity present in an already licensed vaccine for protection against pneumococcal diseases.

\section{Final comments}

After 80 years during which alum was the only licensed adjuvant, some new formulations were approved for human use in the last two decades. Recent advances in the understanding of how innate mechanisms influence the adaptive immunity have led to a more rational design of new adjuvant formulations. One of the key features of an efficient adjuvant formulation is the activation of innate immunity by PAMPs and DAMPs and it seems that the presence of redundant signals leads to more efficient priming of protective and long-lasting immunity against a pathogen. The combination of several adjuvants has proven to be an efficient strategy for delivery of multiple activation signals and some adjuvant systems are already used in vaccines available for human use. However, such adjuvant formulations can significantly enhance the cost of production of vaccines, which makes their use in lowincome countries quite difficult. It is thus crucial to keep in mind that all the recent advances in the understanding of the mechanisms of action of adjuvants must be translated into products that developing countries can afford. Otherwise, the great majority of the world's population will not gain any benefit from this knowledge. In this regard, one example of an alternative approach for the production of a low-cost adjuvant is the production of MPL derived from LPS obtained from $B$. pertussis. This LPS is a by-product of the process for the production of the whole cell pertussis vaccine with lower endotoxin content ( $\left.w \mathrm{P}_{\text {low }}\right)$ and therefore a vaccine and an adjuvant are obtained in a same production plant in a single fermentation. Moreover, this MPL combined with seasonal or pandemic influenza vaccines was effective in mice and was able to reduce the amount of antigen necessary for achieving protective titers $(76,77)$. Reduction of antigen content can then lead to a substantial increase in the number of vaccine doses produced, a very important issue in the case of pandemics, or to extend the vaccination programs to other target populations at risk. Another strategy that can be cost-effective is to present several signals for the activation of the innate immune system during the immunization with a purified antigen through the simple co-administration with whole-organism vaccines that are already licensed and proven to be safe. The combination of wP (alone or as a component of DTP) with the pneumococcal antigen PspA triggering protective responses against a pneumococcal challenge in mice is one example of such strategy. Such a combined vaccine would also have a very low production cost, which would greatly facilitate its use in developing countries and would thus have a major impact on public health.

A final and important consideration is that any new vaccine formulation derived from low-cost and efficient adjuvants must be extensively tested for safety, since, in principle, they could be pro-inflammatory. This is an important concern for maintaining high levels of confidence 
in vaccines (78), which are usually greater among populations in developing countries than in industrialized countries (79). Taking into account all of these features will permit the introduction of new essential vaccines and the maintenance of the current programs always based on and supported by impartial and unbiased epidemiological studies.

\section{References}

1. Plowright $\mathrm{W}$. The duration of immunity in cattle following inoculation of rinderpest cell culture vaccine. J Hyg 1984; 92: 285-296.

2. Normile D. Animal science. Rinderpest, deadly for cattle, joins smallpox as a vanquished disease. Science 2010; 330: 435.

3. Zepp F. Principles of vaccine design-Lessons from nature. Vaccine 2010; 28 (Suppl 3): C14-C24.

4. De Gregorio E, Tritto E, Rappuoli R. Alum adjuvanticity: unraveling a century old mystery. Eur J Immunol 2008; 38: 2068-2071.

5. Cooper MD, Alder MN. The evolution of adaptive immune systems. Cell 2006; 124: 815-822.

6. Kawai T, Akira S. Toll-like receptor and RIG-I-like receptor signaling. Ann N Y Acad Sci 2008; 1143: 1-20.

7. Rehwinkel J. Exposing viruses: RNA patterns sensed by RIG-I-like receptors. J Clin Immunol 2010; 30: 491-495.

8. Dam TK, Brewer CF. Lectins as pattern recognition molecules: the effects of epitope density in innate immunity. Glycobiology 2010; 20: 270-279.

9. Kerrigan AM, Brown GD. C-type lectins and phagocytosis. Immunobiology 2009; 214: 562-575.

10. Figdor CG, van Kooyk Y, Adema GJ. C-type lectin receptors on dendritic cells and Langerhans cells. Nat Rev Immunol 2002; 2: 77-84.

11. Schlee M, Hartmann G. The chase for the RIG-I ligand recent advances. Mol Ther 2010; 18: 1254-1262.

12. Netea MG, van der Meer JW. Immunodeficiency and genetic defects of pattern-recognition receptors. N Engl J Med 2011; 364: 60-70.

13. Kawai T, Akira $\mathrm{S}$. The role of pattern-recognition receptors in innate immunity: update on Toll-like receptors. Nat Immunol 2010; 11: 373-384.

14. Bell JK, Mullen GE, Leifer CA, Mazzoni A, Davies DR, Segal DM. Leucine-rich repeats and pathogen recognition in Toll-like receptors. Trends Immunol 2003; 24: 528-533.

15. Kim D, Kim YJ, Koh HS, Jang TY, Park HE, Kim JY. Reactive Oxygen Species Enhance TLR10 Expression in the Human Monocytic Cell Line THP-1. Int J Mol Sci 2010; 11: 3769-3782.

16. Akira S, Takeda K. Toll-like receptor signalling. Nat Rev Immunol 2004; 4: 499-511.

17. Akashi-Takamura S, Miyake K. TLR accessory molecules. Curr Opin Immunol 2008; 20: 420-425.

18. Youn JH, Oh YJ, Kim ES, Choi JE, Shin JS. High mobility group box 1 protein binding to lipopolysaccharide facilitates transfer of lipopolysaccharide to CD14 and enhances lipopolysaccharide-mediated TNF-alpha production in human monocytes. J Immunol 2008; 180: 5067-5074.

19. Piccinini AM, Midwood KS. DAMPening inflammation by

\section{Acknowledgments}

The authors would like to thank FAPESP, CNPq, and Fundação Butantan for financial support. P.L. Ho would like to thank Prof. Ricardo Galler (Fiocruz, RJ) for his encouragement and advice. modulating TLR signalling. Mediators Inflamm 2010; 2010: pii 672395.

20. Lin SC, Lo YC, Wu H. Helical assembly in the MyD88IRAK4-IRAK2 complex in TLR/IL-1R signalling. Nature 2010; 465: 885-890.

21. Akira S. TLR signaling. Curr Top Microbiol Immunol 2006; 311: 1-16.

22. Takaoka A, Yanai H, Kondo S, Duncan G, Negishi H, Mizutani T, et al. Integral role of IRF-5 in the gene induction programme activated by Toll-like receptors. Nature 2005; 434: 243-249.

23. Mata-Haro V, Cekic C, Martin M, Chilton PM, Casella CR, Mitchell TC. The vaccine adjuvant monophosphoryl lipid A as a TRIF-biased agonist of TLR4. Science 2007; 316: 16281632.

24. Martinon F, Mayor A, Tschopp J. The inflammasomes: guardians of the body. Annu Rev Immunol 2009; 27: 229-265.

25. Kanneganti TD, Lamkanfi M, Nunez G. Intracellular NODlike receptors in host defense and disease. Immunity 2007; 27: 549-559.

26. Schroder K, Tschopp J. The inflammasomes. Cell 2010; 140: 821-832.

27. Martinon F, Burns K, Tschopp J. The inflammasome: a molecular platform triggering activation of inflammatory caspases and processing of prolL-beta. Mol Cell 2002; 10: 417-426.

28. Eisenbarth SC, Flavell RA. Innate instruction of adaptive immunity revisited: the inflammasome. EMBO Mol Med 2009; 1: $92-98$.

29. Duncan JA, Bergstralh DT, Wang Y, Willingham SB, Ye Z, Zimmermann AG, et al. Cryopyrin/NALP3 binds ATP/dATP, is an ATPase, and requires ATP binding to mediate inflammatory signaling. Proc Natl Acad Sci U S A 2007; 104: 80418046.

30. Philbin VJ, Levy O. Developmental biology of the innate immune response: implications for neonatal and infant vaccine development. Pediatr Res 2009; 65: 98R-105R.

31. Davis BK, Wen H, Ting JP. The Inflammasome NLRs in immunity, inflammation, and associated diseases. Annu Rev Immunol 2011; 29: 707-735.

32. Mogensen TH. Pathogen recognition and inflammatory signaling in innate immune defenses. Clin Microbiol Rev 2009; 22: 240-273.

33. Franchi L, Amer A, Body-Malapel M, Kanneganti TD, Ozoren $\mathrm{N}$, Jagirdar $\mathrm{R}$, et al. Cytosolic flagellin requires Ipaf for activation of caspase-1 and interleukin 1 beta in salmonellainfected macrophages. Nat Immunol 2006; 7: 576-582.

34. Miao EA, Alpuche-Aranda CM, Dors M, Clark AE, Bader MW, Miller SI, et al. Cytoplasmic flagellin activates caspase-1 and secretion of interleukin 1 beta via Ipaf. Nat Immunol 2006; 7 : 
569-575.

35. Aimanianda V, Haensler J, Lacroix-Desmazes S, Kaveri SV, Bayry J. Novel cellular and molecular mechanisms of induction of immune responses by aluminum adjuvants. Trends Pharmacol Sci 2009; 30: 287-295.

36. Barrett AD, Teuwen DE. Yellow fever vaccine - how does it work and why do rare cases of serious adverse events take place? Curr Opin Immunol 2009; 21: 308-313.

37. Querec T, Bennouna S, Alkan S, Laouar Y, Gorden K, Flavell $R$, et al. Yellow fever vaccine YF-17D activates multiple dendritic cell subsets via TLR2, 7, 8, and 9 to stimulate polyvalent immunity. J Exp Med 2006; 203: 413-424.

38. McKee AS, Macleod MK, Kappler JW, Marrack P. Immune mechanisms of protection: can adjuvants rise to the challenge? BMC Biol 2010; 8: 37.

39. Coffman RL, Sher A, Seder RA. Vaccine adjuvants: putting innate immunity to work. Immunity 2010; 33: 492-503.

40. Didierlaurent AM, Morel S, Lockman L, Giannini SL, Bisteau $\mathrm{M}$, Carlsen $\mathrm{H}$, et al. AS04, an aluminum salt- and TLR4 agonist-based adjuvant system, induces a transient localized innate immune response leading to enhanced adaptive immunity. J Immunol 2009; 183: 6186-6197.

41. Mbow ML, De Gregorio E, Valiante NM, Rappuoli R. New adjuvants for human vaccines. Curr Opin Immunol 2010; 22: 411-416.

42. Morefield GL, Sokolovska A, Jiang D, HogenEsch H, Robinson JP, Hem SL. Role of aluminum-containing adjuvants in antigen internalization by dendritic cells in vitro. Vaccine 2005; 23: 1588-1595.

43. Li H, Willingham SB, Ting JP, Re F. Cutting edge: inflammasome activation by alum and alum's adjuvant effect are mediated by NLRP3. J Immunol 2008; 181: 17-21.

44. Kool M, Petrilli V, De Smedt T, Rolaz A, Hammad H, van Nimwegen $M$, et al. Cutting edge: alum adjuvant stimulates inflammatory dendritic cells through activation of the NALP3 inflammasome. J Immunol 2008; 181: 3755-3759.

45. Hornung $V$, Bauernfeind $F$, Halle A, Samstad EO, Kono H, Rock KL, et al. Silica crystals and aluminum salts activate the NALP3 inflammasome through phagosomal destabilization. Nat Immunol 2008; 9: 847-856.

46. Franchi L, Nunez G. The Nlrp3 inflammasome is critical for aluminium hydroxide-mediated IL-1beta secretion but dispensable for adjuvant activity. Eur J Immunol 2008; 38: 2085-2089.

47. Eisenbarth SC, Colegio OR, O'Connor W, Sutterwala FS, Flavell RA. Crucial role for the Nalp3 inflammasome in the immunostimulatory properties of aluminium adjuvants. Nature 2008; 453: 1122-1126.

48. Li H, Nookala S, Re F. Aluminum hydroxide adjuvants activate caspase- 1 and induce IL-1 beta and IL-18 release. $J$ Immunol 2007; 178: 5271-5276.

49. Sokolovska A, Hem SL, HogenEsch H. Activation of dendritic cells and induction of CD4(+) T cell differentiation by aluminum-containing adjuvants. Vaccine 2007; 25: 4575-4585.

50. Alderson MR, McGowan P, Baldridge JR, Probst P. TLR4 agonists as immunomodulatory agents. J Endotoxin Res 2006; 12: 313-319.

51. Warshakoon HJ, Hood JD, Kimbrell MR, Malladi S, Wu WY, Shukla NM, et al. Potential adjuvantic properties of innate immune stimuli. Hum Vaccin 2009; 5: 381-394.

52. Leroux-Roels G. Unmet needs in modern vaccinology: adjuvants to improve the immune response. Vaccine 2010; 28
(Suppl 3): C25-C36.

53. Stoute JA, Slaoui M, Heppner DG, Momin P, Kester KE, Desmons $P$, et al. A preliminary evaluation of a recombinant circumsporozoite protein vaccine against Plasmodium falciparum malaria. RTS,S Malaria Vaccine Evaluation Group. N Engl J Med 1997; 336: 86-91.

54. Bejon P, Lusingu J, Olotu A, Leach A, Lievens M, Vekemans $\mathrm{J}$, et al. Efficacy of RTS,S/AS01E vaccine against malaria in children 5 to 17 months of age. N Engl J Med 2008; 359: 2521-2532.

55. Kasturi SP, Skountzou I, Albrecht RA, Koutsonanos D, Hua $\mathrm{T}$, Nakaya $\mathrm{HI}$, et al. Programming the magnitude and persistence of antibody responses with innate immunity. Nature 2011; 470: 543-547.

56. PAHO. Immunization newsletter. Edition Washington 2007; 1-8.

57. Marr N, Novikov A, Hajjar AM, Caroff M, Fernandez RC. Variability in the lipooligosaccharide structure and endotoxicity among Bordetella pertussis strains. J Infect Dis 2010; 202: 1897-1906.

58. Zorzeto TQ, Higashi HG, da Silva MT, Carniel EF, Dias WO, Ramalho VD, et al. Immunogenicity of a whole-cell pertussis vaccine with low lipopolysaccharide content in infants. Clin Vaccine Immunol 2009; 16: 544-550.

59. Hicks LA, Harrison LH, Flannery B, Hadler JL, Schaffner W, Craig AS, et al. Incidence of pneumococcal disease due to non-pneumococcal conjugate vaccine (PCV7) serotypes in the United States during the era of widespread PCV7 vaccination, 1998-2004. J Infect Dis 2007; 196: 1346-1354.

60. Singleton RJ, Hennessy TW, Bulkow LR, Hammitt LL, Zulz T, Hurlburt DA, et al. Invasive pneumococcal disease caused by nonvaccine serotypes among Alaska native children with high levels of 7 -valent pneumococcal conjugate vaccine coverage. JAMA 2007; 297: 1784-1792.

61. Oliveira ML, Miyaji EN, Ferreira DM, Moreno AT, Ferreira PC, Lima FA, et al. Combination of pneumococcal surface protein $A(P s p A)$ with whole cell pertussis vaccine increases protection against pneumococcal challenge in mice. PLoS One 2010; 5: e10863.

62. McGuirk $\mathrm{P}$, Mills $\mathrm{KH}$. A regulatory role for interleukin 4 in differential inflammatory responses in the lung following infection of mice primed with Th1- or Th2-inducing pertussis vaccines. Infect Immun 2000; 68: 1383-1390.

63. Fedele G, Spensieri F, Palazzo R, Nasso M, Cheung GY, Coote JG, et al. Bordetella pertussis commits human dendritic cells to promote a Th1/Th17 response through the activity of adenylate cyclase toxin and MAPK-pathways. PLoS One 2010; 5: e8734.

64. Fischer JE, Johnson JE, Johnson TR, Graham BS. Pertussis toxin sensitization alters the pathogenesis of subsequent respiratory syncytial virus infection. J Infect Dis 2000; 182: 1029-1038.

65. McGuirk P, Johnson PA, Ryan EJ, Mills KH. Filamentous hemagglutinin and pertussis toxin from Bordetella pertussis modulate immune responses to unrelated antigens. $J$ Infect Dis 2000; 182: 1286-1289.

66. Munro P, Flatau G, Anjuere F, Hofman V, Czerkinsky C, Lemichez E. The Rho GTPase activators CNF1 and DNT bacterial toxins have mucosal adjuvant properties. Vaccine 2005; 23: 2551-2556.

67. Poulain-Godefroy O, Vendeville C, Locht C, Riveau G. Bordetella pertussis filamentous hemagglutinin delivered by 
mucosal routes enhances immunoglobulin levels in serum and mucosal fluids. FEMS Immunol Med Microbiol 2008; 54: 129-136.

68. Fischer JE, Johnson TR, Peebles RS, Graham BS. Vaccination with pertussis toxin alters the antibody response to simultaneous respiratory syncytial virus challenge. J Infect Dis 1999; 180: 714-719.

69. Nasso M, Fedele G, Spensieri F, Palazzo R, Costantino $\mathrm{P}$, Rappuoli R, et al. Genetically detoxified pertussis toxin induces Th1/Th17 immune response through MAPKs and IL-10-dependent mechanisms. J Immunol 2009; 183: 18921899.

70. Kerfoot SM, Long EM, Hickey MJ, Andonegui G, Lapointe $\mathrm{BM}$, Zanardo RC, et al. TLR4 contributes to diseaseinducing mechanisms resulting in central nervous system autoimmune disease. J Immunol 2004; 173: 7070-7077.

71. Racke MK, Hu W, Lovett-Racke AE. PTX cruiser: driving autoimmunity via TLR4. Trends Immunol 2005; 26: 289-291.

72. Tonon S, Badran B, Benghiat FS, Goriely S, Flamand V, Willard-Gallo K, et al. Pertussis toxin activates adult and neonatal naive human CD4+ T lymphocytes. Eur J Immunol 2006; 36: 1794-1804.

73. Mielcarek N, Riveau G, Remoue F, Antoine R, Capron A, Locht C. Homologous and heterologous protection after single intranasal administration of live attenuated recombinant Bordetella pertussis. Nat Biotechnol 1998; 16: 454-457.

74. Eskola J, Olander RM, Hovi T, Litmanen L, Peltola S, Kayhty
$H$. Randomised trial of the effect of co-administration with acellular pertussis DTP vaccine on immunogenicity of Haemophilus influenzae type b conjugate vaccine. Lancet 1996; 348: 1688-1692.

75. Dagan R, Goldblatt D, Maleckar JR, Yaich M, Eskola J. Reduction of antibody response to an 11-valent pneumococcal vaccine coadministered with a vaccine containing acellular pertussis components. Infect Immun 2004; 72: 5383-5391.

76. Quintilio W, Kubrusly FS, lourtov D, Miyaki C, Sakauchi MA, Lucio F, et al. Bordetella pertussis monophosphoryl lipid A as adjuvant for inactivated split virion influenza vaccine in mice. Vaccine 2009; 27: 4219-4224.

77. Miyaki C, Quintilio W, Miyaji EN, Botosso VF, Kubrusly FS, Santos FL, et al. Production of H5N1 (NIBRG-14) inactivated whole virus and split virion influenza vaccines and analysis of immunogenicity in mice using different adjuvant formulations. Vaccine 2010; 28: 2505-2509.

78. Poland GA, Spier R. Fear, misinformation, and innumerates: how the Wakefield paper, the press, and advocacy groups damaged the public health. Vaccine 2010; 28: 2361-2362.

79. Mulholland K, Korczak V, Tangcharoensathien V. Confidence in vaccines in developing countries: social, cultural, economic and political influences. J Epidemiol Community Health 2010; 64: 563-564.

80. Pashine A, Valiante NM, Ulmer JB. Targeting the innate immune response with improved vaccine adjuvants. Nat Med 2005; 11: S63-S68. 